\title{
METACOGNITIVE LEARNING STRATEGY: IN SEARCH OF THEORETICAL MODEL FOR READING COMPREHENSION
}

\author{
Iswan Riyadi $^{1}$, Hersulastuti ${ }^{2}$, Th. Kriswianti Nugrahaningsih ${ }^{3}$ \\ iswanriyadi@gmail.com ${ }^{1}$ \\ Universitas Widya Dharma Klaten ${ }^{1,2,3}$
}

\begin{abstract}
This paper was presented on the basic of senior high school teachers' complaint over the implementation of scientific- based approach in 2013 Indonesian National Curriculum. Their path to successful learning is obstructed by the discontinuity of five stages of scientific- based approach which comprises of observing, questioning, associating, experimenting, and networking. This study was aimed at developing a theoretical model of reading comprehension based on metacognitive learning strategies. Descriptive qualitative approach was carried out to determine some possible theories which might lead to coin the theoretical model of reading comprehension based on metacognitive learning strategies for Indonesian students of Senior High School. Results of the study showed that underlining, note taking, summarizing, concept mapping might also be instantly working together to help senior high school students get the text content well-comprehended.
\end{abstract}

Keywords: Learning process; Metacognition; Metacognitive strategies.

\section{INTRODUCTION}

The implementation of 2013 Indonesian National Curriculum has mandated that scientific based approach is implemented to addres affective, cognitive and psychomotoric domain to convey the lesson content so that student is expected to 'know-why', 'know-how', 'know-what'.The final result would be expected that there will be balanced improvement between students' soft skill and hard skills .

A capable learning model is needed to guaratee that scientific -based approach learning will run smoothly. The reason is previous observation, showing that almost the majority of teachers in all subject lessons have difficulty to go on with the next steps (questioning) as students are not able to do the first step (observing). Reading text is considered best way to go on to the next step. Students' deficiency in comprehending text has long been the weakest point in performing scientific based approach.

Good reading skill will be crucial for students when they must read the text before going onward to the questioning step. Students with low reading text capability have been proven to have low score in implementing reading strategies compared to those who have better reading skill, particularly in using their cognitive and metacognitive competence (Chan, 2003:177). Metacognitive awareness and then use of cognitive and metacognitive strategies has close relation with the efficiency of reading process (Magogwe.J.M, 2013). In the context of learning activities, metacognitive strategies are students' behaviour, planning and evaluating their own learning. Within the strategies, a certain attention and self evaluation, arranging time, goal, and keep on searching new method are included. In reading context, self monitoring, error finding, 
are advanced stage in metacognitive strategies (Singhal: 2001). Instructing and habituating to use metacognitive strategies in reading text will help students to have deep understanding the text content to ensure that scientific based approach learning runs smoothly.

Hattie (2008) had convinced many scholars that students achievement will significantly improve as teachers constantly execute intervention rather than just performing a facilitator.. Mokhtari \& Sheorey (2002:3) found that teachers intervention which helps improving students metacognitive strategies awareness will enable them to gain better learning achievement.

\section{RESULT AND DISCUSSION}

\section{Metacognition Theory}

Metacognition began to be a formal study in 1979's through several case studies on children memorization, directed to understand thinking process in the school learning as well as to find out a teaching strategy which enable students to get an effective learning (Flavel \& Wellman,1977). It was found in the result that there was knowledge disparity among children concerning their cognitive process (Metacognitive knowledge control) and cognitive control to be autonomous learner to do particular task (metacognitive experience). The research concluded that both aspects worked together completely each other; the first is then called declarative knowledge and the later is known as procedural knowledge.

Again, Flavell (1979) revealed metacognition from students' development perspective to make monitoring on their thinking skill by exploring what to be monitored (metacognitive knowledge), which will grow experience, set the goal to reach understanding and using strategies to reach the goals as well as making self evaluation. The process will produce the development of metacognitive skill. Flavell's model of metacognition can be observed below

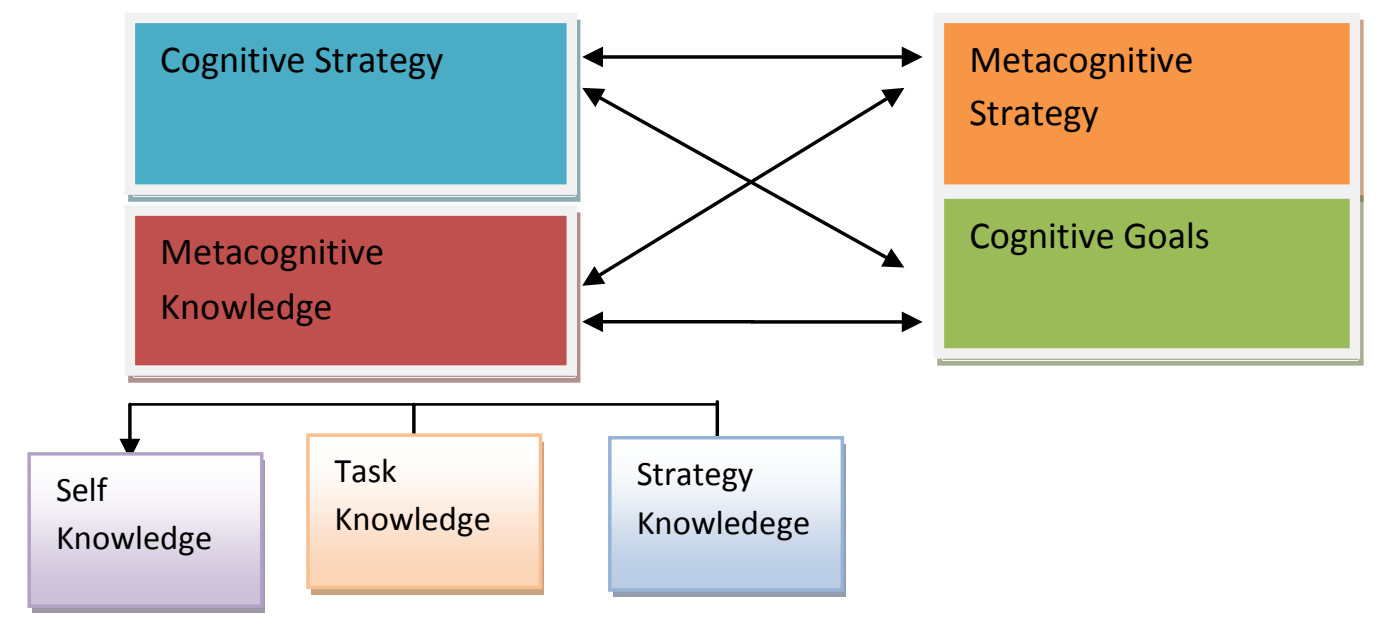

Figure 1. Flavell's Metacognitive Model 
Slightly different from Flavell, Brown ( 1983 ) devided metacognition in to two considerable parts. The first is correlated with cognitive knowledge concerning the reflection of activity and cognitive ability. This category encompasses conscious reflection while doing the tasks. The second component of metacognition is correlated with self regulation during the process of learning activity or problem solving. This is what Brown mention about cognitive regulation

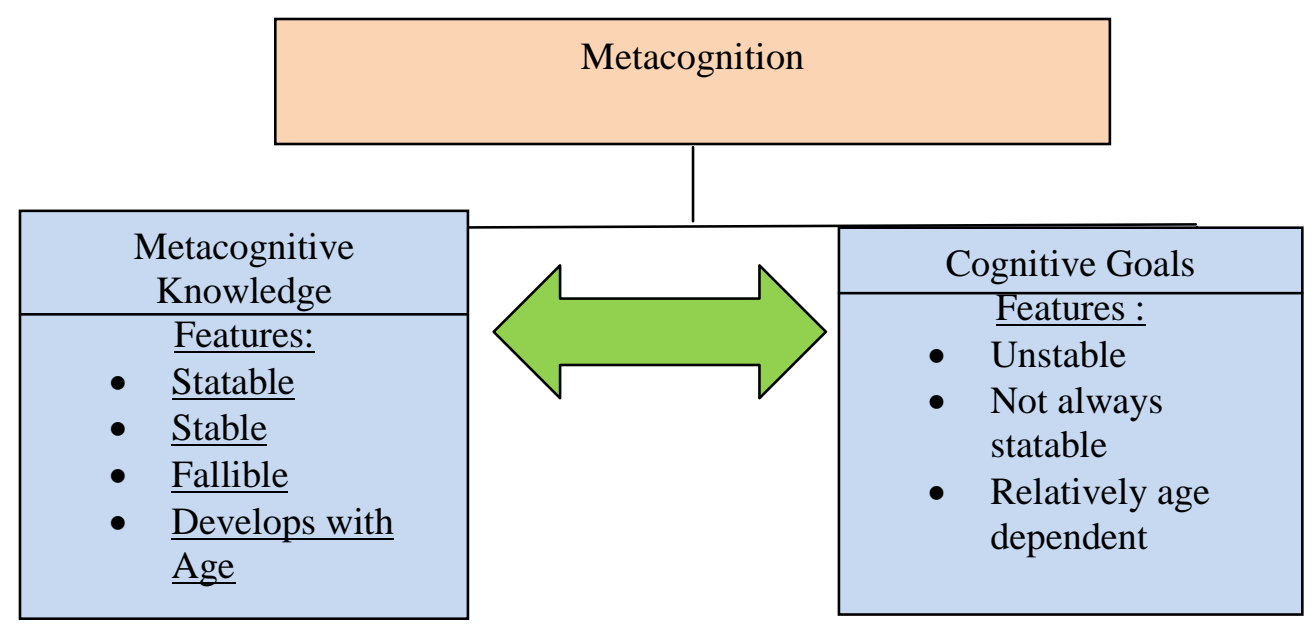

Figure 2. Brown's Model of Metacognition

According to Brown, cognitive knowledge and cognitive regulation are close to each other. Cognitive knowledge is stable and it is often too late to come to students' thinking development. In the early, metacognition is understood as 'knowing about knowing”.. Meanwhile cognitive regulation consists of activities directed to control and regulate learning activities. Some aspects which include in this process are planning, monitoring activities and evaluating. Brown believes that good learner will equip him/herself with high order metacognitive awareness and be able to strategically monitor and evaluate his/her learning activities.

Nowadays metacognition has gripped many researchers to be developed in education context resulting enormous researches and academic articles with more complexity of metacognitive theoretical aspects which leads to conceptually narrowing the structure of metacognition

However, this still leaves confuses in several things even it has widely implemented (Zohar,A \& David,A.B, 2009) First, there is no firm border line between cognition and metacognition. Second, researchers often make use of similar term, that is metacognition, even when they refer to different aspect from the complexity of concept that exist in metacognition itself. Other crucial thing that obscures the real meaning of metacognition is the relationship among various metacognitive components that researchers use to discuss. Conceptual distraction about the concept of metacognition with its sub-components has invited various parties to raise conceptual and theoretical concerning this terms clarification

Veenman (2006) viewed several terms within the umbrella of metacognition involve metacognitive belief, metacognitive awareness, metacognitive experience, metacognitive knowledge, metamemory, metacognitive skill, executive skill, higher order skill, metacomponent, learning strategies, heuristic strategy, and self-regulation. 
Parts of the terms refer to more general knowledge and skill, while some others contain specific meaning that refers students' age. Further, Veenman (2006) specifically mentioned" ...some of them relate to both cognitive and metacognitive processes (eg; learning strategies and heuristic strategies), whereas others are purely metacognitive by nature...”. In case of metacognition with self-regulated learning, for instance, Dinsmor (2008) was the first one to question the existence of conceptual fuzzy meaning between metacognition, self-regulation and self-regulated learning. The conceptual distinction of the three concepts has been searched its rooted theories from various literatures.

Kaplan (2008) clearly coined the existence of close intersection between 'cognition' vs 'behavior', and 'individual' vs 'environment'. Dinsmor (2008) more clearly placed the core meaning of metacognition as a focus on individual cognition, self-regulation as a focus on behavior which is a result of interaction between individual and his environment, and self-regulated learning as a fussion of both. In this point, Kaplan (2008) assumed that Dinsmor didn't clearly show the difference conceptually as metacognition is yet influenced by environment, and self-regulation still incorporates individual cognition.

The subject of debate in search of clearer clarification on the meaning of metacognition, self-regulatory, self-regulated learning are still required, particularly how to make more conceptual tools to distinguish those three terms, not just finding out theoretical borders. Veenman (2006) declared that there has been researchers' consistent understanding on the importance of metacognition, but inconsistency raises in its construct conceptualization.

\section{Metacognition in learning strategies.}

Most of metacognitive learning strategies literatures are connected with the area of self management skills as metacognitive learning strategies refers to students' ability to monitor and be aware of their learning process. (Pintrich.2002)

Hence, more and more education scientists suggest teachers and students to make use of metacognitive strategies as they have proven to be successful bringing students into their deep understanding about their knowledge and ability to automatically control and cultivate their cognitive process (Venus, L.B. 2015)

Riyadi, Hersulastuti, Kriswianti (2016), through scientific journals search, found some metacognitive strategies which separately have proven to be effective in assisting Junior High School students reading comprehension. The study found interesting evidence, that is, teachers intervention using metacognitive learning strategies ; underlining/highlighting, summarizing, note taking and concept mapping, simultaneously help students understand the content of text book . In addition to better achievement in reading comprehension, learning atmosphere becomes alive and joyful.

\section{a.Underlining/Highlighting}

One's metacognitive skill will play better in almost the area of cognitive process. The effect of metacognition on students' achievement have long been proven through its component; metacogntive awareness, metacognitive regulation, metacogniative knowledge. Several reserches have revealed that students' achievement could be better as they are able to use their metacogntive skill while executing the schooling tasks .(Al Alwan,2011; Penagos, 2013; Pinniti, 2016 ). 
In reading context, for instance, students' ability to implement metacognitive strategies will help them to better comprehension of the text (Tagivezhad, 2015;.Mc.Cabe, 2011; Leutwyer, B. 2009). While reading, one has actually been exerting his capability to make decision about 'what might be important' and 'what not' to be emphasized to take into the account. The most easier and popular way students use to do is underlining or highlighting some words or sentence to mark them out as important part of the text (Rosenthal, 2000)

In the activity of underlining, one is actually using his/her metacognitive knowledge to make text marking which leads students to a deeper text information process than they would when simply reading it.(Fowler \& Baker 1974; Nist \& Hogrebe 1987) .In line with this idea, many studies concerning the effect of underlining showed that students's skill in using underlining strategy will lead to succesful understanding the text content.(Yue,C.L, Storm,B.C,2015; Price,K.W,Elizabeth,2012)

In contrast to these arguments, others argued that underlining parts of text in passages as a merely learning strategy has shown to be less effective than simple rereading (Marxen, Dale 1996; Schnell,Thomas 1978; Garner Ruth, 1990). These researchses revealed strong belief that when students have great deal of well- organised and accessible conceptual knowledge, they don't rely on reading or learning strategies.

\section{b. Note Taking}

It is believed that students' notes which are written in class during the lesson or while reviewing a course material or comprehending a text are essential tool for learning. Good note-taking practices can lead to efficient study practices, better course outcomes, and improve retention of content beyond a course's conclusion. It is because learning can occur during both the production and review of notes by allowing learners to make connections between the idea units and engage in deep processing of course content (Bohay, Bakely, Tamplin, \& Radvansky, 2011).

Specifically in reading context, some metacognition skills are used as students do note-taking to comprehend the text. Many mental processes occur simultaneously during the act of note-taking in order to understand the content of the text, to identify what is important to write, and type their notes. Hence, in note- taking, the complexity of the cognitive operations and the knowledge involved, require students to actively control what they are doing and to master the way they work. It occurs when they develop their cognition and skills to sort out the important information to foster a better understanding of the text they are reading. The process begins as students use their knowledge and activate schemata in the process of systematizing, interpreting, organizing and using that information for further details for creating a note. Boch (2001) mentions this metacognitive knowledge leads students to plan their activity, to evaluate it, and to regulate it. In this way the notes can be functioned as external storage that are placed and written out for the purpose of later reference. By making notes while reading will keep the students' brain actively looking for connections and later making connections of how learning works, so it can prevent students from becoming passive.

Note -taking is a strategy to improve learning of both oral and written materials. It is a beneficial technique for studying the content, developing language skills, and learning task in general (White, 1996). Hebert, Graham, Wills \& Ganson (2014) prove that note-taking is useful tool for improving students' reading comprehension. The beneficial effect of note taking covers two major functions as process and product 
(Kiewra, 1987, Robinson, Katayama, Odom, Beth, Hsieh, \& Vanderveen, 2006). First, the process of recording notes facilitates learning. It works well to increase students' attention, to raise awareness of text organization, and to store the information into memory. Second, the notes, as product serve as an external storage of information that is useful to retrieve the content in delayed recalls or answering some exam questions.

Other evidences have demonstrated that metacognition works in note- taking in various contexts of learning. Romainville \& Noel (2003) apply this metacognitive approach to note- taking to help students overcome the numerous difficulties they have at the beginning of their studies at university. They provide students with a situation that are meaningful for them to learn and they are assigned to make notes of the lecture. At the end of the task, students are helped to deploy a metacognitive conceptualization by filling a questionnaire, then the answers are analyzed in pairs. The analysis can be used to map type of difficulties students face during learning and can function as a feed back for better improvement. In lower grade, Trawick-Smith (2003) confirm that children at primary schools are found metacognitively capable in directing their own memory processes, organizing information, and paying attention to important information. This indicates that students already possess the cognitive capacities needed for note-taking. Strengthening to this point, it is recommended that students at young age can be instructed to develop note-taking ability to promote learning (Lee. Lan, Hamman \& Hendricks, 2007). Moreover, in different context, Hartley (2002) claims note- taking as an effective information-processing tool that is commonly used both in daily life and in many professions. Note- taking helps someone to carry out of a range of intellectual processes, especially in making judgments, resolving issues, and further making decisions.

\section{c. Summarizing}

Writing summary is a way to improve a better comprehension while reading. It is the most important thing to help students retain what happened in the reading process. In summarizing a text, students work back and forth between the text by rereading, rewriting, and continually reflecting on and comparing aspects (Kirkland \& Saunders, 1991). Brown Day, and Jones (1983) claim that the transfer effects of summarization have usually been explained using a metacognitive structure. In relation with reading comprehension, metacognition refers to a reader's awareness and control of the reading process. When it relates to summary writing, the use of metacognitive strategies helps the writer summarize the text more effectively through the use of selecting, planning, interracting, monitoring, and so forth (Rinehart, Stahl, \& Erickson, 1986). In short, the metacognition process is started with the decision to select which of the most important points of the text as the key information to be written. Summarizing is not a recapitulation of the material. It is a reviewing process of what students have known about the existing knowledge into working memory, and then making access to that knowledge faster. This process enhances students ability to make connections between the existing knowledge and what happens in the process of summarizing. Reviewing the summary of the text that has been read is a way to move what students have learned from short-term to long-term memory. Summarization is believed to facilitate learning because it helps readers clarify the meaning and significance of discourse. In this case, students who cannot summarize a text appropriately, they are often considered to have comprehended the text inappropriately (Kim, 2001) 
Even though summarizing text proves its merits in helping students to comprehend the text better, however, students in any levels still need to improve their summarization skills. Brown, et.al.(1983) reveal that even older learners are not particularly adept at summarizing text. They experience difficulty, especially in reducing text to its gist in the absence of space constraints. In addition, some less proficient readers highlight information of personal interest in the summary rather than emphasize textually important information. This happens as teachers rarely include summary writing instructions in their lessons. They argue that there is not much time allotted to teach writing, whereas they know that as a part of the regular curriculum, teachers can include summary writing integrated into their lessons in an effort to enhance their students' reading comprehension (Cho, 2012)

There have been many studies conducted by researchers to improve summarizing skills. In Turkish context, Diliduzgun, Sukran, Genc, and Serife (2015) believe that comprehending essays is important for cognitive and intellectual development. Castro, and Carolyn (2006) demonstrate that teaching outlining and raising L2 learners' awareness of text structure results in improved comprehension, more detailed and organized summaries, therefore teachers are recommended to provide students with various strategies training to improve their summarizing skills. Elliott (2007) in seeking an effective technique for improving her students' summarizing skills, she implements a new strategy of drawing after reading in her classroom. It is purposed to both motivate students and engage them in the reading process, while at the same time improving their comprehension. The results show that drawing after reading can actively engage students. When students summarize the text by drawing, they must form a visual representation of the information they are trying to convey. This provides opportunities for students to elaborate and encode the information in more personal and meaningful way. In conclusion, drawing after reading help students reflect on what they have read and allows time to process the information.

With regard to the research findings above, it is believed that students who have good summarizing skills will lead them have a better comprehension skills as well. It is because summary writing is regarded as an integrative task that involves the interplay of two abilities- the ability to understand the main ideas and rhetorical organization of a text and the ability to succint and coherent restatement of the author's gist (Enrich, Grabe, Koda, Mosenthal, Ernt, \& Schedl, 2000).

\section{Concept Mapping}

The concept map was first introduced by Joseph D Novak in 1972, as he was working with his students at Cornell University. Then in 1984 Novak and Gowin established this theory by basing on the principle of meaningful learning. They explained that concept maps are schematic tools for explaining the relationship of meaning and understanding. They described the concept map as a visual map showing the plots to relate the meaning of the concepts (Novak \& Gowin, 1984). Concept maps help both students and teachers to see the key ideas that they need to take in order to do specific tasks, and once the tasks are done, concept maps also help them to make summaries easier to evaluate (Novak Gowin, 1084). Concept maps help students connect concepts visually and develop a deeper understanding of interconnected relationships. Students using concept maps can recognize new associations and new meanings that they have previously unconsciously believed before using concept maps. Concept maps are used to evaluate how students organize their knowledge and give an 
observable record of their understanding (Novak \& Gowin (1984), concept maps are generally seen as a useful learning tool in the classroom. Concept maps help students learn the key concepts and their associations in the solution methods of structural analysis problems. (Trifone, 2006)

Edmondson, K. (1994) looks at concept maps as being very useful for making the structure of knowledge clearer and clearer. An important concept map in relation emphasizes the summary of key thoughts of the material being studied. Concept maps also help to synthesize and identify key thoughts, themes, and interrelationships, especially for students who do not have the skills to organize and synthesize. In this connection Kim, Vaughn, Wanzek and Wei (2004) explain that visual presentation of information as presented in concept maps improves reading comprehension for students with learning barriers, and can help them organize verbal information to improve their memory.

Mintzes, Wandersee \& Novak, (1997) describe concept maps as "metacognitive tools" which encourages students to think reflectively about what they know through the visual representation of the meaning and relationship of concepts. While McAleese (1998) states that the process of making concept maps involves making decisions about how concepts relate to one another, leading individuals to reflect on prior knowledge as they relate to new material. Brown (1987) wrote that the concept mapping process also involves controls in the planning process, progress monitoring, and evaluation of goal attainment when maps are constructed.

Cassata (2006) describes that a concept mapping task is useful to enhance the learning experience of preschool children by facilitating metacognitive skills involving planning, prediction, correcting errors and evaluating progress. The steps to make concept map are (Cassata and French 2006): 1) concept selection; 2) concept placement; and 3) concept connection. At every steps, learner are trained to make planning, monitoring of progress, and create opportunities for reflection. In many cases, concept maping also helps students to choose the right method to solve a problem. (Trifone 2006); (Zwaal and Otting 2012); (Sarker 2015). In reading context, it is believed as a learning strategy which can have any scaffolding effect on the reading comprehension (Tajeddin, Zia, Tabatabaei, Soudabeh, 2016; Kuo EnChang, Yao Ting Sung, Ine Dai Chen, 2002)

\section{CONCLUSION}

After being faced by real character and the advantages and disadvantages of the four strategies, we realize that they have been playing significant role in helping students comprehend text content much better. But we do believe when they could be performed together as a solid and compact tool for class learning process they will be more effective. Moreover, they will be best performed when teachers make intervention by making use of them on the learning process.

\section{REFFERENCES}

Aleese Ray Mc. (1998). The Knowledge Arena as an Extension to the Concept Map: Reflection in Action, Interactive Learning Environment. 6(10), 1-2

Alwan-Al, (2008). The Effect of Using Metacognition Reading Strategies on the Reading Comprehension of Arabic Texts. IJAES. 13(1), 1-17.

Boch, F. (2001). Note-taking as writing to learn at University. Pratiques, 105/106, 137-159

Bohay, M., Blakely, D.P., Tamplin, A.K., \& Radvansky, G.A. (2011). Note-taking. Review, memory, and comprehension. The American Journal of Psychology, 124, 63-73. 
Brown, A. L. (1987). Metacognition, executive control, self-regulation, and other more mysterious mechanisms. In F.E. Weinert \& R.H. Kluwe (Eds.), Metacognition, motivation, and understanding (pp. 65-116). Hillsdale, NJ: Erlbaum.

Brown, A.L., \& Day, J.D. (1983). Macrorules for summarizing text: The development of expertise. Journal of Verbal Learning and Verbal Behavior, 22, 1-14

Cassata E. Amy, Lucia French. (2006). Using Concept Mapping To Facilitate Metacognitive Control In Preschool Children. Paper presented at The Second International Conference on Concept Mapping. San José, Costa Rica,

Castro, \& Carolyn, D. (2006). Improving L2 Reading and Summarizing Skills through Explicit Instruction in Text Structure. Vigo International Journal of Applied Linguistics 3.5978.

Chan , D.W., (2003). Reading strategy use and motivation among Chinesse good and poor readers in Hong Kong, Journal of Research in Reading 26(2) 177-190

Cho, Y. (2012). Teaching Summary Writing through Direct Instruction to Improve Text Comprehension for Students in ESL/EFL Classroom. A Master's Paper. University of Wisconsin-River Falls.

Diliduzgun, Sukran, Genc, \& Serife (2015). Improving summarizing skills through text structure-based strategies. International Bibliography of the Social Sciences (IBBS).

Dinsmor. D., Alexander. P., Loughlin, S.M. (2008). Focusing on the Conceptual Lens on Metacognition, Self Regulation, and Self Regulated Learning. Educational Psichological Review 20, 477-484.

Edmondson, K.M, (1994). Concept maps and the development of cases for problem based learning, Journal of the Association of American Medical Colleges, 69(2), 108-110.

Elliott, J. (2007). Summarizing with drawings: a reading-comprehension strategy. Science Scope. 23-27.

Enrich, M.K., Grabe, K.. Koda,K., Mosenthal, P., Mulcahy- Ernt, P., \& Schedl, M.A. (2000). TOEFL 2000 Reading Framework: A working Paper. Princeton, NJ: Educational Testing Service.

Flavell, J, Wellman, H.M., (1977). Metamemory; Perspective on the development of memory and cognition, Hillsdale, NJ, Erlbaum.

Flavell, J. (1979). Metacognition and cognitive monitoring. American Psychologist, 34(10), 906-911.

Fowler, R.L., Barkes, A.S. (1974). Effectiveness of Hightlighting for Retention of Text Material. Journal of Applied Psycghology, 59, 358-364.

Garner, Ruth (1990) When Children and Adults Do Not Use Learning Strategies: Toward a Theory of Setting, Review of Educational Research 60(4), 517-529.

Georghiades, P. (2000). Beyond Conceptual Change Learning In Science Education: Focusing On Transfer, Durability And Metacognition. Educational Research, 42(2), 119-140.

Hartley (2002). Note-taking in non academic settings: a review. Applied Cognitive Psychology, $16,559-574$.

Hattie, J. (2009). Visible Learning; A Synthesis of Over 800 Meta Analyses Relating to Achivement, Oxon, New York: Routledge,

Hebert, M,. Graham, S., Wills, H.R., \& Ganson, K. (2014). Effects of Note-taking and Extended Writing on Expository Text Comprehension: Who benefits? A Contemporary Journal, $12(1), 43-68$.

Hidi, S., \& Anderson. V. (1986). Producing Written Sumaries: Task Demands, Cognitive Operations, and Implications for Instruction. Review of Educational Research 56 (4), 473-493.

Kaplan, A. (2008). Clarifying Metacognition, Self Regulation, Self Regulated Learning : What's the Purpose? Educational Psichological Review, 20, 477-484.

Kiewra, K.A. (1987). Note- taking and review: The research and its implication. Instructional Science, 16, 233-249. 
Kim, S.E. (2001). Characteristic of EFL Readers' Summary Writing: A Study with Korean University Students. Foreign Language Anals 34(6), 569-581.

Kirkland, M., \& Saunders, S. (1991). Maximizing Students Performance in Summary Writing: Managing Cognitive Load. TESOL QUARTERLY, 25(1), 105-121.

Kuo EnChang, Yao Ting Sung, Ine Dai Chen, (2002). The Effect of Concept Mapping to Enhance Text Comprehension and Summarization. The Journal of Experimental Education, 71(1), 5-23.

Lee, P.L., Lan, W., Hamman, D., \& Hendricks, B. (2008). The effect of teachng note-taking strategies on elementry students' science learning. Instr Sci. 36,191-201.

Leutwyer, B. (2009). Metacognitive Learning Strategies: Differential Development Patterns in High School, Metacognitive Learning 4: 111-123.

Magogwe, J.M. (2013). Metacognitive Awareness of Reading Strategies of Universities of Botswana, Reading and writing, 4(1) 1-8.

Marxen, Dale. (1996). Why Reading and Undetlining a Passage Is a Less Effective Study Strategy Than Simply Reading the Passage, Reading Improvement, 33(2), 88-96.

Cabe, Mc. (2011). Metacognitive Awareness of Learning Strategies in Undergraduates, Mem.Cogn, 39, 462-476.

Mintzes J.J., Wandersee J.H., \& Novak, J.D. (1997). Teaching science for understanding. San Diego, CA: Academic Press.

Mokhtari, K \& Sheorey, R, (2002). Measuring ESL students' awareness of reading strategies. Journal of Development Education 25, 2-10.

Nist,S.L. \& Hogrebe (1987) The Role of Underlining and Annotating in Remembering Textual Information, Reading Research and instruction 27, 12-25.

Penagos, H.P (2011) How Can Metacognition be Developed through Problem-Solving in Higher Education, Ingeniera E Investigacion, 31, 213-223.

Pintrich, H.P.R, (2002). The Role of Metacognitive Knowledge in Learning, Teaching, and Assesing, Theory Into Practice, 41, 219-225.

Price, Elizabeth (2012). Silent Reading Fluency Using Underlining: Evidence for An Alternative Method of Assement, Psychology in the School, 49(6) 606-618.

Robinson, D, H., Katayama, A.D., Odom, S., Beth, A., Hsieh, Y.P., \& Vanderveen, A. (2006). Increasing text comprehension and graphic note-taking using a partial organizer task. Journal of Educational Research, 100, 103-111.

Riyadi, I., Hersulastuti, Kriswianti, Th. (2015). Pengembangan Model Pembelajaran Membaca Pemahaman Berbasis Strategi Belajar Metakognisi. Kemenristek Dikti: Laporan Hasil Penelitian Hibah Pascasarjana.

Romainville, M. \& Noe, B (2003). Metacognition and Note-taking learning at the University. Arobase, 1-2, 87-96

Rosenthal (2000) Metacognition And Higher Order Thoughts, Conciousness and Cognition, 26, 231-242.

Singhal, M. (2001). Reading, proficiency, reading strategies, metacognitive awareness, and L2 learners, The Reading Matrix.

Schnell, Thomas (1978). A Comparison of Underlying Strategies for Improving Reading Comprehension and Retention, Reading Horizon, Vol. 18(2), 106-109.

Tajeddin, Zia, Tabatabaei, Soudabeh (2016). Concept Mapping as a Reading Strategy: Does It Scaffold Comprehensioon and Recall? Reading Matrix An International Online Journal, 16(1). 194-208.

Taginezhad (2015). The Influence of Teachuing Metacognitive Reading Strategies on the Reading Self-Efficacy Beliefs of Iranian EFL Learners, Modern Journal of Language Teaching Methods, 4(5), 728-734.

Trawick-Smith, J. (2003). Early childhood development, a multicultural perspectives. Upper Saddle Rve, New Jersey: Merril Prentice Hall.

Veenman M.V.J \& Bernadette (2006) Metacognition and learning: conceptual and methodological considerations. Metacognition Learning 1: 3-14. 
Venus, L.B. (2015). The Effect of Metacognitive Learning Strategy in Physic Achievement, The International Journal of Science \& Technolodge, 3, 9-21.

White, C.J. (1996). Note-taking and traces of cognition in language learning. RELC Journal. 27, 89-1032.

Yue, C.L. (2015). Highlighting and Its Relation to Distributed Study and Students' Metacognitive Beliefs, Educational Psychology Review, 27, 69-78.

Zohar, A. \& David (2009). Paving a clear path in a thick forest: a conceptual analysis of a metacognitive component. Metacognition Learning, 4: 177-195 
